\title{
Desenvolvimento Profissional e Educação Especial
}

Professional Development and Special Education

Glaé Corrêa Machado'; Andréia Mendes dos Santos ${ }^{1}$

\section{RESUMO}

Esta pesquisa aborda a construção do desenvolvimento profissional dos professores, assim como as formações e as experiências inclusivas que os transformaram em professores da Educação Especial e Inclusiva, a partir de narrativas de professoras da Educação Básica. Estudo de cunho qualitativo, que a partir do processo de análise identificam-se quatro dimensões as quais apresentam as possibilidades e os caminhos encontrados. A primeira indica os diálogos e as reflexões sobre a iniciação profissional e as motivações para a escolha. A segunda revela os diálogos e reflexões sobre a formação e a experiência profissional, que implicam um investimento pessoal, com vistas à construção de uma identidade, que é também profissional. A terceira traz os diálogos e reflexões sobre a educação especial e inclusiva e o desenvolvimento profissional, sendo necessário propor alternativas inclusivas para a educação e não apenas para as escolas. A quarta e última, remete aos diálogos e reflexões sobre as transformações profissionais, e nesse sentido, compreendeu-se que a formação do professor é um processo que ocupará toda sua permanência profissional.

Palavras-chave: Desenvolvimento Profissional de Professores; Educação Especial; Educação Inclusiva.

\begin{abstract}
This research addresses the construction of teachers' professional development, as well as the training and inclusive experiences that made them teachers of Special and Inclusive Education, based on narratives of teachers of Basic Education. A qualitative study, which from the analysis process identifies four dimensions which present the possibilities and the paths found. The first indicates the dialogues and reflections on professional initiation and the motivations for choosing. The second reveals the dialogues and reflections on training and professional experience, which imply a personal investment, with a view to building an identity, which is also professional. The third brings dialogues and reflections on special and inclusive education and professional development, and it is necessary to propose inclusive alternatives for education and not just for schools. The fourth and last, refers to the dialogues and reflections on professional changes, and in this sense, it was understood that teacher education is a process that will occupy all their professional permanence.
\end{abstract}

Keywords: Teacher Professional Development; Special education; Inclusive education.

\footnotetext{
1 PUCRS - Pontifícia Universidade Católica do Rio Grande do Sul, Porto Alegre/RS - Brasil.
} 


\section{INTRODUÇÃO}

Motivada pelas palavras de Freire (1996) de que "[...] a experiência da abertura como experiência fundante do ser inacabado que terminou por se saber inacabado. Seria impossível saber-se inacabado e não se abrir ao mundo e aos outros à procura de explicação, de respostas a múltiplas perguntas. [...]" (p. 153-154), surgiu o interesse em pesquisar sobre a construção do desenvolvimento profissional dos professores, assim como as formações e as experiências inclusivas que os transformaram em professores da Educação Especial e Inclusiva. O cenário deste estudo é o município de Montenegro/RS, que possui uma rede com 27 escolas que atendem a educação infantil e o ensino fundamental, com aproximadamente 450 professores e 6.000 alunos.

As participantes escolhidas para essa pesquisa foram cinco professoras da rede municipal de Montenegro, que atuam na Educação Básica nos níveis da Educação Infantil e do Ensino Fundamental, realizando o Atendimento Educacional Especializado nas Salas de Recursos Multifuncionais. Os critérios utilizados para o convite levaram em consideração o interesse das professoras em participar da pesquisa, além de mais de 10 anos de experiência docente, participação nas formações oferecidas pela rede municipal na área da educação especial e experiência com alunos com deficiência e/ou necessidades educacionais especiais. Essa escolha foi intencional, uma vez que as professoras com as quais atuo em minha rede de ensino despertaram em mim o estímulo e o desafio para esta pesquisa. Na observação de suas práticas pedagógicas e no trabalho em parceria, surgiu o interesse em investigá-las, principalmente, porque muitas delas têm realizado trabalhos pioneiros em relação à inclusão de alunos nos segmentos onde atuam.

A relevância deste estudo apoia-se na perspectiva de que nós, professores, buscamos em nossa profissão, possivelmente, respostas às indagações existenciais de quem está impelido a entender para melhor realizar as tarefas em que empenha consigo, com seus alunos, ou mesmo formando outros professores. Enquanto sujeito que aprende, constituído pelo que aprende, o homem não pode desvincular o que faz no mundo daquilo que faz de si mesmo, por sua capacidade de reflexão. $\mathrm{Na}$ ótica de Osório Marques (2003), "[...] na articulação dessas duas instâncias - o eu e o mundo consiste a capacidade de reflexão, isto é, a posse de seus saberes sobre si mesmo e seu mundo" (p. 41).

Somos diferentes, essa é a nossa condição humana. Pensamos, agimos e sentimos de jeitos, formas e com intensidades diferentes. $E$ tudo isso porque vivemos e apreendemos o mundo de forma diferente uns dos outros. Conforme Edler Carvalho, "[...] a questão não é se queremos ou não ser diferentes, mas que, como seres humanos, nossa identidade depende substancialmente da diversidade, da dignidade e da alteridade, porque precisamos garantir o caráter subjetivo de nossa individualidade" (2006, p.11). Desse modo, pensar a prática da inclusão significa tomar consciência e valorizar, não apenas compreender e aceitar, a diversidade humana. Muitas questões se transformam, os certos e os errados passam a ser relativizados e problematizados e, a partir daí, começamos a compreender o caráter reducionista das classificações impostas a esse alunado.

A sociedade inclusiva e a escola inclusiva, como ideais, têm angariado a simpatia dos pais, dos professores e da sociedade em geral. Afinal, o movimento de não excluir está implícito nos ideais democráticos, aceitos e proclamados, universalmente. No entanto, a história das ideias sobre a educação deixa evidente que pouco ou nada tinha de inclusiva, seja em termos de universalização do acesso, seja em termos da qualidade do que era oferecido. Na atualidade, o panorama é, felizmente, 
outro, pois há mais consciência acerca de direitos humanos, embora a prática da proposta de educação inclusiva ainda não conte com o consenso e unanimidade, mesmo entre aqueles que defendem a ideia.

Sou uma profissional que acredita na Educação Inclusivai e que luta pela implantação dessa prática no sistema de ensino no qual atuo, mas percebo que muitos professores são resistentes às políticas educacionais, como a inclusão. A tendência é os professores considerarem a proposta de uma educação para todos válida, porém utópica, impossível de ser concretizada devido ao número de alunos e às circunstâncias em que se trabalha, hoje, nas escolas, principalmente na rede pública de ensino, o que é compreensível.

Nós, professores, como qualquer ser humano, tendemos a adaptar uma situação nova às anteriores. E o que é habitual, no caso dos cursos de formação inicial e na formação continuada, é a separação entre teoria e prática, sobretudo quando essa formação é superficial ou inexistente, como no caso da inclusão. Essa visão dicotômica do ensino dificulta a nossa atuação, como formadores, sobretudo no que diz respeito à prática da educação inclusiva.

Também reconheço que as mudanças nas políticas educacionais abalam nossa identidade profissional e o lugar conquistado por nós, professores, em uma dada estrutura ou sistema de ensino, atentando contra nossa formação, nossa experiência, nossos saberes e conhecimentos e o esforço que fizemos para adquiri-los. Por isso, é fundamental pesquisar sobre o desenvolvimento profissional dos professores atuantes na Educação Especial, e como seus percursos formativos e suas experiências contribuem na construção de uma carreira voltada para a Educação Inclusiva.

Dessa forma, creio ser importante reforçar que esta pesquisa abarca duas temáticas relevantes para lidar com essa problemática encontrada em nossos sistemas de ensino, sendo elas: o Desenvolvimento Profissional dos Professores e a Educação Especial na perspectiva da Educação Inclusiva, com apoio em autores como Benjamin, Freire, Aranha, Batista, Edler Carvalho, Fernandes, Jesus, Josso, Jovchelovitch \& Bauer, Lüdke e André, Mantoan, Marcelo Garcia, Mazzota, Minayo, Montero, Nóvoa, Osório Marques, Pimenta, Sarmento, Sassaki, Tardif e Lessard, entre outros; essa diversidade de referenciais se fez necessária pela complexidade do tema e das temáticas por ele abarcada. Para dar andamento a essa pesquisa, definiu-se como questão central: Como os percursos formativos e as experiências docentes em educação especial contribuem na construção do desenvolvimento profissional dos professores numa perspectiva inclusiva?

Essa pesquisa intencionou uma melhor compreensão dos professores que atuam na educação especial e do investimento realizado no seu desenvolvimento profissional, a partir da percepção e da necessidade de buscar uma educação de boa qualidade para todos, que inclua a diversidade existente em nosso ambiente educacional, sem, no entanto, ter a pretensão de indicar soluções ou receitas, mas mostrar as possibilidades existentes e próximas da nossa realidade.

\section{PERCURSO METOdOLÓGICO}

As orientações metodológicas que adotei nesse trabalho estão baseadas na perspectiva de pesquisa qualitativa, conforme Lüdke e André (1986). Essas autoras destacam as seguintes características básicas de uma pesquisa qualitativa: ter o ambiente natural como fonte direta de dados, os quais devem ser predominantemente descritivos, existir uma preocupação muito maior com o processo do 
que com o produto, perceber o significado que as pessoas dão às coisas. É necessário retratar, ainda, a perspectiva dos participantes. Nesse sentido, para o desenvolvimento dessa pesquisa me inspirei nos critérios recorrentes da Narrativa. Na perspectiva de Jovchelovitch \& Bauer (2002), trata-se de um método de pesquisa muito difundido nas Ciências Sociais, pois tem em vista uma situação que encoraja e estimula um entrevistado a contar a história sobre algum acontecimento importante de sua vida e do contexto social. Com base nessas crenças, explicito os passos que foram dados nessa investigação: os instrumentos, a coleta e a análise dos dados coletados, a partir dos procedimentos metodológicos por mim elencados.

\section{INSTRUMENTOS}

A escolha da Narrativa como metodologia para essa pesquisa qualitativa leva em consideração o que Jovchelovitch \& Bauer (2002, p.110) apresentam como características das narrativas em relação à realidade propriamente dita e à representação dessa realidade, uma vez que ela privilegia a realidade do que é experienciado pelos contadores de história e refere-se ao que é real para esse contador, assim como expressam a verdade de um ponto de vista, de uma situação específica no tempo e no espaço. A narrativa é o processo de ressignificação do acontecimento narrado, em momentos de imbricação entre personagem e pesquisador e essa experiência ocorre na interação que se dá entre os dois sujeitos históricos. A utilização da narrativa como instrumento de pesquisa, no sentido atribuído por Benjamin (1996), coloca o pesquisador como participante da história de seus personagens, a partir do momento em que ele é também participante nessa reconstrução. Os instrumentos utilizados para coleta de dados nesta pesquisa são narrativas escritas, apoiados nos fundamentos de Cunha (1998, p.38), que afirma: "as narrativas dos sujeitos são a sua representação da realidade e, como tal, estão prenhes de significados e reinterpretações (...)".

A escolha das narrativas escritas justifica-se, segundo Cunha (1998, p.40), por elas representarem "um processo profundamente emancipatório em que o sujeito aprende a produzir sua própria formação, autodeterminando a sua trajetória". Permitir-se protagonizar a própria vida implica, entre outras coisas, desconstruir e reconstruir as próprias experiências, através da memória e da materialização de lembranças. De acordo com Josso (2004, p.186), a narrativa escrita apresenta-se, "como uma tentativa de dar acesso a um percurso interior que evolui correlativamente (...) para um percurso exterior caracterizado por acontecimentos, atividades, deslocamentos, relações contínuas e encontros, pertenças etc." Na condição de pesquisadora, trabalhei consciente de que o ato narrativo se fundamenta na memória do narrador, e que a significação dada ao fato no momento de seu acontecimento é ressignificada no momento da enunciação desse fato, em virtude de que a memória é reconstrutiva, além de ser seletiva. Eu observei esse aspecto durante a investigação. Contudo, é significativo o esclarecimento de Cunha (1998, p.9) sobre a reinterpretação de significados, mostrando que "uma narrativa acaba sempre sendo um processo cultural, pois tanto depende de quem a produz como depende de para quem ela se destina".

\section{COLETA E ANÁLISE DE DADOS}

No andamento da pesquisa, a coleta de dados compreendeu dois movimentos: no primeiro, solicitei às professoras escolhidas a produção de narrativas escritas e individuais, na qual contaram suas histórias pessoais e profissionais, assim como suas experiências em relação à educação especial e inclusiva. 
No segundo movimento, fiz a devolução das narrativas, marcadas pelo diálogo e por entrevistas com as professoras participantes acerca da experiência de refletir sobre aspectos de sua vida pessoal e profissional, movimento pouco utilizado no cotidiano dos professores, mas considerado por mim como significativo e formador. As narrativas foram elaboradas no mês de setembro de 2016 e as entrevistas foram realizadas no mês de outubro de 2016.

Na sequência desses movimentos, foi necessário olhar atentamente para os dados da pesquisa, pois durante a fase da coleta de dados, a análise já estava ocorrendo. Portanto, encarei as narrativas não apenas como instrumentos e procedimentos metodológicos, mas fiquei atenta aos fatos, diálogos, depoimentos e impressões que fossem significativos e produzissem sentido em relação à construção pelos professores do seu desenvolvimento profissional numa perspectiva inclusiva.

Para a análise dos dados coletados, segui a proposta de Jovchelovitch \& Bauer (2002), os quais sugerem a transcrição e a análise temática, como uma das formas de analisar as pesquisas que têm como caminho metodológico as narrativas. Segundo os autores acima citados, o primeiro passo na análise dos dados foi a conversão deles, através da transcrição das narrativas. Seguindo as orientações de Jovchelovitch \& Bauer (2002), de que "[...] a transcrição, por mais cansativa que seja, é útil para se ter uma boa apreensão do material, e por mais monótono que o processo de transcrição possa ser, ele propicia um fluxo de ideias para interpretar o texto" (p.106), nessa perspectiva reescrevi todas com esse intuito.

Na análise temática, foi necessário construir um referencial de codificação, por isso os autores recomendavam que fosse um procedimento gradual de redução do texto qualitativo. As unidades do texto foram progressivamente reduzidas em duas ou três rodadas de séries de paráfrases.

Num primeiro momento, passagens inteiras ou parágrafos foram parafraseados em sentenças sintáticas. Estas sentenças foram posteriormente parafraseadas em palavras-chave. Ambas as reduções operaram com generalizações e condensações de sentido. Na prática, o texto foi colocado em três colunas: a primeira contendo a transcrição, a segunda contendo a primeira redução e a terceira coluna contendo apenas palavras-chave (JOVCHELOVITCH \& BAUER, 2002).

A partir desse parafrasear, desenvolveu-se um sistema de dimensões com o qual todos os textos foram, em última análise, codificados, quando necessário. O produto final constituiu uma interpretação das narrativas, juntando as estruturas de relevância dos informantes com as do pesquisador. A fusão dos horizontes dos informantes e do pesquisador é algo que tem a ver com a hermenêuticaii (JOVCHELOVITCH \& BAUER, 2002).

Por último, ocorreu o tratamento e a interpretação dos dados que, como sinaliza Brandão (2003), "[...] em boa medida, é para essa etapa que convergem todas as outras, embora ela não seja a última" (p.250). Conforme o autor, todo o trabalho feito até então, processado e ordenado nas etapas anteriores, foi agora submetido ao estudo e às descrições, às comparações e às interpretações partilhadas por mim e minha orientadora. 


\section{RESULTADOS E CONCLUSÕES}

No intuito de sinalizar os achados dessa pesquisa, sem, contudo conferir-lhe status de conclusão definitiva, exponho as possibilidades e os caminhos encontrados sob a forma de quatro sínteses temáticas:

A primeira síntese temática indica os diálogos e as reflexões sobre a iniciação profissional, tanto minha enquanto pesquisadora quanto das professoras participantes dessa pesquisa. A análise mostra que nossas motivações para a escolha profissional foram permeadas por relações afetivas repletas de encantamento e conscientes da importância e da responsabilidade assumida pela profissão professor, mas ao mesmo tempo com autonomia e admiração; vejo que nossas iniciações foram caracterizadas pelas fases de sobrevivência e descoberta, período em que encontramos situações inesperadas e, às vezes, difíceis de serem enfrentadas (HUBERMAN,1992), mas, também, período rico na construção de saberes especificamente ligados às práticas e as experiências pedagógicas no campo profissional (TARDIF, 2002); outro aspecto relevante refere-se a nossa disposição constante de autocrítica e autoanálise sobre os trabalhos desenvolvidos, nosso interesse pela formação e reflexão, por planejamentos bem estruturados e por trocas de experiências, pois conscientes de nosso inacabamento, compreendemos estar em constante processo de aprendizagem, considerando-nos professoras aprendentes (FREIRE, 1996); também me deparo com os desafios do início da carreira, que tiveram a tarefa de servir como estimulantes para continuarmos nossa caminhada, entretanto, observo que ao enfrentar desafios e o medo frente às novas situações, encontramos outros questionamentos e dúvidas, mas que estes, sempre serviram para nos impulsionar.

A partir dessa primeira síntese e amparada por Josso (2006), valho-me de nossas histórias, juntamente com o que elas representam, para extrair delas o que penso ter contribuído para nos tornarmos o que somos, o que sabemos sobre nós mesmas e sobre nosso ambiente humano e natural e tentar compreendê-las melhor, foi o grande desafio dessa proposta. O trabalho narrativo biográfico não consistiu apenas em revelar as lembranças pertinentes aos questionamentos que orientaram essa pesquisa, foi o momento de compreender como nossa história articulou-se como um processo - o processo de formação - que pôde ser compreendido mediante as lições das lembranças que articularam nosso presente ao passado e ao futuro (JOSSO, 2006, p. 376).

Na segunda síntese temática, tenho os diálogos e reflexões sobre a formação e a experiência profissional, movimento por mim realizado no capítulo inicial deste estudo e pelas professoras participantes ao longo de suas narrativas biográficas. Minha compreensão foi de que estar em formação implica um investimento pessoal, um trabalho livre e criativo sobre os percursos e os projetos próprios, com vistas à construção de uma identidade, que é também uma identidade profissional, sendo assim, nossa atuação profissional tem seus pressupostos voltados ao aprendizado e domínio das condições materiais para o exercício profissional; nosso processo de formação depende dos nossos percursos educativos, são ações contínuas e progressivas, que envolvem diversos aspectos e outorgam relevância significativa para a prática pedagógica e para a experiência profissional, lembrando que nossa atuação profissional engloba saberes específicos, saberes pedagógicos e saberes construídos na experiência (TARDIF, 2002 e GAUTHIER, 2006); constato também que os movimentos de formação continuada devem fazer parte das preocupações da escola que deseja um corpo docente atualizado e esclarecido, uma vez que projetos de atualização, círculos de debates, grupos de reflexão, organização de painéis, de palestras, são iniciativas que podem estabelecer um programa enriquecedor de formação continuada, em benefício de todos os 
profissionais da escola; concluo ainda que o conceito de desenvolvimento profissional tem o sentido de evolução e continuidade que supera a tradicional justaposição entre formação inicial e continuada dos professores, e que, as atividades de desenvolvimento profissional não afetam apenas nós, professores, mas todos aqueles com responsabilidade ou implicação no aperfeiçoamento da escola (NÓVOA, 1992a).

Em consonância com a segunda síntese e com os estudos de Josso (2004), observo que o formador forma-se a si próprio, a partir da reflexão sobre os seus percursos pessoais e profissionais (autoformação); da relação com os outros, numa aprendizagem conjunta que faz apelo à consciência, aos sentimentos e às emoções (heteroformação); por intermédio dos saberes, técnicas, culturas, artes, tecnologias; e pela compreensão crítica (ecoformação).

O trabalho com narrativas de vida possibilita explicitar singularidades, vislumbrar o universal e perceber o caráter processual da formação e da vida. Elas apontam possibilidades de mediações capazes de redescobrir essas dimensões esquecidas do imaginário, e mostrar como tais dimensões permanecem vivas dentro de nós. Tais dimensões mostram, também, a possibilidade de, olhando um pouco no que nos tornamos, darmos passagem a outras formas de vida, numa invenção de si, na produção de um coletivo mais saudável (JOSSO, 2004).

A terceira síntese temática traz os diálogos e reflexões sobre a educação especial/inclusiva e o desenvolvimento profissional, na qual compreendo educação especial como um recurso que beneficia a todos os alunos e que atravessa o trabalho de todos nós, professores, com toda a diversidade que constitui nosso grupo de alunos, sendo necessário propor alternativas inclusivas para a educação e não apenas para a escola; observo que a quebra de estereótipos e preconceitos, ponto de partida para a implantação de uma escola inclusiva, faz-se necessária para que o modelo que aí está se rompa; constato a necessidade da colaboração e da cooperação entre todos os participantes do processo educacional, principalmente de nós, professores, na tentativa de mudar papéis e responsabilidades, tornando o ambiente educacional mais flexível (EDLER CARVALHO, 2006); evidencio que a formação continuada é uma das estratégias que permite desacomodar o instituído, substituindo-o por novas teorias e novas práticas alicerçadas em outra leitura de mundo, principalmente, na crença da riqueza das potencialidades humanas, as nossas e as dos nossos alunos; concluo que a educação especial/inclusiva exige de nós, professores, uma mudança de postura, no sentido de redefinir nosso papel, que é fundamental no desenvolvimento de nosso aluno e no nosso desenvolvimento profissional para atuar nesse processo inclusivo; e por fim, lamento que falte à maioria de nós, professores, o despertar do espírito de pesquisadores (MANTOAN, 2005 e 2006).

Intervir nas questões da identidade, expressões de nossa existencialidade, através da análise e da interpretação das narrativas biográficas escritas, permite colocar em evidência a pluralidade, a fragilidade e a mobilidade de nossas identidades ao longo da vida, e que de acordo com Josso (2007, p. 415-416):

[...] é por essa razão que essas identidades num constante vir-a-ser, manifestação de nossas existencialidades em movimento, são em certos períodos históricos mais fortemente atingidas pelos efeitos desestruturadores de mudanças sociais, econômicas e/ou políticas. 
Abordar o conhecimento de si mesmo pela categoria das transformações do ser - sujeito vivente e conhecente no tempo de uma vida, através das atividades, dos contextos de vida, dos encontros, acontecimentos de sua vida pessoal e social e das situações que ele considera formadoras e muitas vezes fundadoras, é conceber a construção da identidade, como um conjunto complexo de componentes (JOSSO, 2007, p. 420). Josso (2004) ainda atrela o ato de aprender ao ato de pesquisar, pois acredita que este possibilitaria aos aprendentes o desenvolvimento da sua criatividade, habilidade, capacidade de avaliação, comunicação e negociação, como percebo nos movimentos pessoais e profissionais relatado por todas as professoras participantes dessa pesquisa, inclusive por mim.

Por fim, mas sem a pretensão de concluir este percurso, apresento a quarta e última síntese temática, que nos remete aos diálogos e reflexões sobre as (trans) formações profissionais, e nesse sentido, compreendo que a formação do professor é um processo que ocupará toda sua permanência em sua atividade profissional, distinguindo assim três grandes componentes estruturais: a formação inicial, a formação contínua e a formação especializada, no entanto, nenhum desses componentes funciona separadamente, a sua articulação com os restantes é inevitável (MARCELO GARCIA, 1992a e 1999); observo que o professor necessita conhecer profundamente as disciplinas e os conteúdos que leciona, mas precisa igualmente conhecer o meio social dos alunos com os quais trabalha e as características da comunidade em que atua, como precisa compreender o desenvolvimento dos seus alunos e as diferentes concepções de educação (TARDIF, 2002); reconheço que a curiosidade dessas professoras impulsionou-Ihes a buscar maior compreensão do contexto, conhecendo melhor seus alunos e, ao mesmo tempo, impulsionando-as para outras aprendizagens; afirmo a relevância da escola, em possibilitar e estimular o desenvolvimento profissional de seus professores, lembrando que a aprendizagem da profissão professor se faz no cotidiano e no enfrentamento das situações que surgem dentro do processo de ensino e aprendizagem, mas também argumento que as partilhas e as trocas de experiências enriquecem o professor na construção de seu percurso formativo (NÓVOA, 1992a).

Assim, as transformações nas quais as pessoas se engajaram podem resultar de uma emergência interior ou ter sido provocada pelo meio ambiente. O ser-sujeito é levado a gerenciar essa coexistência de lógicas de evolução e a viver, dessa maneira, uma tensão mais ou menos forte entre identidade para si e identidade para os outros. A consciência de ser sujeito de sua história, através de todos os ajustes que foi preciso fazer, permite ter a medida do que está em jogo em toda a formação: a atualização do sujeito num querer e poder ser e vir-a-ser e sua objetivação nas formas socioculturais visadas, as que já existem ou as que ele tiver que imaginar. (JOSSO, 2007, p. 423)

De acordo com Josso (2004), para quem experiência é a vivência carregada de significado, é a vivência da qual nos tornamos conscientes, o relato das professoras pesquisadas corrobora, pois, segundo as mesmas, a vivência com alunos com deficiência, única possibilidade para uma mudança que se tornou produtora de novos paradigmas. Josso (2004), ao se referir à aprendizagem pela experiência, faz uma distinção entre vivência e experiência. Para a autora, vivência está relacionada aos acontecimentos, e ela atinge o significado de experiência quando é realizado um trabalho reflexivo sobre o que se passou, situação que as participantes dessa pesquisa vivenciaram/experienciaram ao longo do processo.

Para Josso (2004), uma vivência torna-se experiência quando conseguimos articular o processo de formação e o processo de conhecimento, quando prestamos atenção no que se passa em nós ou na 
situação na qual estamos implicados pela nossa presença. A reflexão sobre a vida é centrada nas experiências que consideramos significativas para compreendermos o que nos tornamos, de que forma chegamos a pensar o que pensamos de nós mesmos, dos outros e do nosso mundo humano e natural.

O percurso desta investigação apontou para a necessidade e a importância das vivências/experiências para a efetivação das práticas inclusivas. Nesse sentido, contei com o conceito de experiência formadora de Josso (2004), segundo o qual "[...] qualquer prática deixa traços; que toda tomada de consciência cria novas potencialidades; e que a transformação é um processo que se desdobra em razão de um caminhar interior mais ou menos consciente antes de se tornar visível para o outro" (p.145).

Esses caminhos para a Educação Inclusiva foram percorridos com dedicação, busca constante e abertura ao novo, por todas as participantes da pesquisa, e que pude experienciar como possibilidade de formação e transformação, na esperança de uma educação para todos, que em última instância, foi e é o grande objetivo vislumbrado pelo nosso trabalho enquanto professoras. Nessa perspectiva e apoiada nessas reflexões, este estudo não teve a pretensão de indicar soluções ou receitas, mas oportunizou uma melhor compreensão da tese que defendi e pude fundamentar, de que a construção do desenvolvimento profissional dos professores se deu a partir de suas formações e experiências com a Educação Especial numa perspectiva inclusiva.

\section{CONSIDERAÇÕES FINAIS}

Inspirada em Josso (2010), encarei a narração da vida como uma ficção, certamente baseada em fatos reais. Essa narração ficcional me permitiu a invenção de um eu autêntico. Sem esquecer que a invenção de si necessita, não somente de um discurso sobre si, mas de projetos de si, o que tive o prazer de concretizar através desse estudo, e constatei que, de fato, nossa história de formação só é possível como processo de conhecimento de sujeito que empreende e, portanto, imagina poder vir a ser sujeito pleno.

Assumir a educação como escolha pessoal e profissional foi uma decisão responsável e apaixonada, mas apostar numa perspectiva educacional como a Educação Especial/Inclusiva foi e é um desafio, o que, segundo Freire (1996, p.88), exige acreditar que "[...] a mudança do mundo implica a dialetização entre denúncia da situação desumanizante e o anúncio de sua superação, no fundo, 0 nosso sonho", pois é "[...] a partir desse saber fundamental: mudar é difícil, mas é possível, que vamos programar nossa ação político-pedagógica, não importa o projeto com o qual nos comprometemos". Assumir esse desafio e escolhê-lo como objeto dessa investigação significa uma busca por possibilidades e conhecimentos, ainda escassos ou pouco difundidos nessa área, porém cada vez mais necessários e urgentes.

Desafiada pelas perspectivas profissionais e as oportunidades dos últimos anos, ingressei em 2013 no Curso de Doutorado em Educação da PUCRS, motivada a pesquisar e aprender mais, e a partir da importância dos estudos sobre a construção dos saberes necessários à educação inclusiva, surgiu o interesse pelo desenvolvimento profissional dos professores, assim como pelas experiências inclusivas que os transformaram em professores da Educação Especial/Inclusiva. 
Como forma de alcançar as possibilidades que esse processo investigativo intencionou sinalizar, destaco as narrativas das professoras e seu processo de análise temática como dados significativos e que me auxiliaram nessa caminhada. Enfatizo que este estudo oportunizou a reflexão sobre a prática de todas as professoras envolvidas, assim como sobre minha própria prática, e uma melhor compreensão dos nossos processos formativos, experienciais e inclusivos, suas complexidades e especificidades.

\section{REFERÊNCIAS}

ANDRÉ, Marli Eliza Dalmazo Afonso de. Pesquisa em educação: buscando rigor e qualidade. Cadernos de Pesquisa. n. 113, p. 51-64, jul. 2001.

BENJAMIN, Walter. Magia e técnica, arte e política. In: Obras escolhidas. São Paulo: Brasiliense, 1996. v.1.

BOBBIO, Norberto. Igualdade e Liberdade. Rio de Janeiro: Ediouro, 3.ed., 1997.

BOGDAN, Robert; BIKLEN, Sari. Investigação qualitativa em educação. Porto: Porto Editora, 1994.

BRANDÃO, Carlos Rodrigues. A pergunta a várias mãos: a experiência da pesquisa no trabalho do educador. São Paulo: Cortez, 2003.

CAVACO, Maria Helena. Ofício do professor: o tempo e as mudanças. In: NÓVOA, A. (Org.). Profissão professor. Porto: Ed. Porto, 1999. p. 155-191.

CORTELLA, Mario Sérgio. A escola e o conhecimento: fundamentos epistemológicos e políticos. São Paulo: Cortez, 2009.

CUNHA, Maria Isabel da. 0 professor universitário na transição de paradigmas. Araraquara: JM Editora, 1998.

EDLER CARVALHO, Rosita. Educação Inclusiva: com os pingos nos "is". 4.ed. Porto Alegre: Mediação, 2006.

FREIRE, Paulo. Pedagogia da autonomia: saberes necessários à prática educativa. 23.ed. São Paulo: Paz e Terra, 1996.

1987.

; SHOR, Ira. Medo e ousadia: o cotidiano do professor. 2.ed. São Paulo: Paz e Terra,

GAUTHIER, Clermont (et. al.). Tradução Francisco Pereira de Lima. Por uma teoria da Pedagogia: pesquisas contemporâneas sobre o saber docente. 2.ed. Ijuí: UNIJUÍ, 2006.

HUBERMAN, M. O. O ciclo de vida profissional dos professores. In: NÓvOA, A. (Org.) Vida de professores. 2. ed. Portugal: Porto Editora,1992. p. 31-61.

JANNUZZI, Gilberta. A luta pela educação do deficiente mental no Brasil. São Paulo: Cortez: Autores Associados, 1985.

JOSSO, Marie-Christine. Experiências de vida e formação. Tradução: José Claudino e Júlia Ferreira. São Paulo: Cortez, 2004. 
- As figuras de ligação nos relatos de formação: ligações formadoras, deformadoras e transformadoras. Educação e Pesquisa. São Paulo, v.32, n.2, p. 373-383, maio/ago. 2006.

. A transformação de si a partir da narração de histórias de vida. Educação. Porto Alegre/RS, ano XXX, n. 3 (63), p. 413-438, set./dez. 2007

. Marie-Christine. Caminhar para si. Tradução: Albino Pozzer. Revisão Maria Helena Menna Barreto Abrahão. Porto Alegre: EDIPUCRS, 2010.

JOVCHELOVITCH, Sandra \& BAUER, Martin. Entrevista Narrativa. In: BAUER, Martin \& GASKELL, George. Pesquisa Qualitativa com texto, imagem e som - um manual prático. 3.ed. Petrópolis, RJ: Vozes, 2002.

LÜDKE, Menga; ANDRÉ, Marli Elisa D. A. Pesquisa em educação: abordagens qualitativas. São Paulo: EPU, 1986.

MANTOAN, Maria Teresa Eglér. Ser ou estar: eis a questão. Explicando o déficit intelectual. Rio de Janeiro: WVA Editores, 1997.

. Uma escola de todos, para todos e com todos: o mote da inclusão. In: STOBÄUS, Claus Dieter; MOSQUERA, Juan José Mouriño. Educação Especial: em direção à educação inclusiva. 2.ed. Porto Alegre: EDIPUCRS, 2004.

. Caminhos Pedagógicos da Educação Inclusiva. In: GAIO, Roberta; MENEGUETTI, Rosa G. K. Caminhos Pedagógicos da Educação Especial. 3.ed. Petrópolis, RJ: Vozes, 2005.

MANTOAN, Maria Teresa Eglér; PRIETO, Rosângela Gavioli; ARANTES, Valéria Amorin. Inclusão Escolar: pontos e contrapontos. São Paulo: Summus, 2006.

MARCELO GARCIA, Carlos. Formação de professores: para uma mudança educativa. Porto: Porto Editora, 1999.

A formação de professores: novas perspectivas baseadas na investigação sobre o pensamento do professor. In: NÓVOA, António. (Coord..). Os professores e a sua formação. Lisboa: Publicações Dom Quixote Instituto de Inovação Educacional, p. 51-76. 1992a.

MAZZOTTA, Marcos J. S. Educação Especial no Brasil: história e políticas públicas. 6.ed. São Paulo: Cortez, 2011.

História da Educação Especial no Brasil. Temas em Educação Especial. São Carlos, Universidade Federal de São Carlos, v.1, p. 106-107. 1990.

Educação Escolar: comum ou especial ? São Paulo: Pioneira, 1987.

MINAYO, Maria Cecília de Souza. Pesquisa Social: teoria, método e criatividade. 24.ed. Petrópolis, RJ: Vozes, 1994.

MONTERO, Lourdes. A construção do conhecimento profissional docente. Lisboa: Instituto Piaget, 2001.

NÓVOA, António (Coord.). Os professores e a sua formação. Lisboa: Publicações Dom Quixote Instituto de Inovação Educacional, 1992a.

NÓVOA, A. O regresso dos professores، Pinhais: Melo, 2011.

OSÓRIO MARQUES, Mario. Conhecimento e Educação. Ijuí: UNIJUÍ, 1988. 
. Pedagogia: a ciência do educador. 2.ed. Ijuí: UNIJUÍ, 1990.

A formação do profissional de educação. 4.ed. Ijuí: UNIJUÍ, 2003.

SACRISTÁN, José Gimeno. Consciência e ação sobre a prática como libertação profissional dos professores. In: NÓVOA, António. Profissão Professor. 2.ed. Porto: Porto Editora, 1999.

SARMENTO, Manuel Jacinto. A vez e a voz dos professores. Porto: Porto Editora, 1994.

TARDIF, Maurice. Saberes docentes e formação profissional. Petrópolis, RJ: Vozes, 2002.

TARDIF; LESSARD, C. 0 trabalho docente: elementos para uma teoria da docência como profissão de interações humanas. Petrópolis, RJ: Vozes, 2005.

' Educação de boa qualidade para todos num sistema educacional que reconheça e atenda às diferenças individuais, respeitando as necessidades de qualquer aluno.

ii Interpretação do sentido das palavras. 